\title{
RESEÑA
}

\section{ARTE, ACTIVISMO Y COMUNICACIÓN EN EL ÁMBITO ACADÉMICO Ana Sedeño-Valdellós (coord.)}

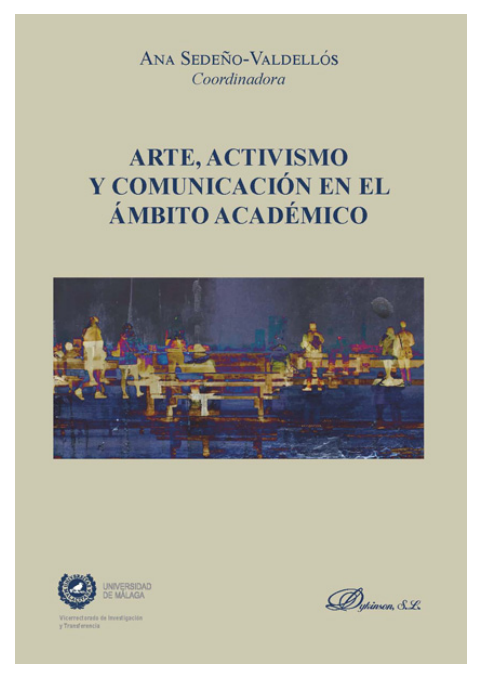

Editorial Dykinson y Universidad de Málaga (Madrid, 2019) ISBN: 978-84-1324-296-5

Páginas: 247

\section{J. Ignacio "Iñaki" Chaves G.}

Grupo de Investigación Laboratorio de Comunicación y Cultura de la Universidad de Málaga

\section{Almudena Barrientos-Báez}

\section{Escuela Universitaria de Turismo Iriarte}

El libro Arte, activismo y comunicación en el ámbito académico coordinado por Ana Sedeño-Valdellós y publicado por el sello editorial de la Universidad de Málaga y Dykinson está financiado por el Plan Propio de Investigación y Transferencia del vicerrectorado de Investigación de la Universidad de Málaga (UMA).

Partiendo de dos premisas: una, la poca información que la ciudadanía española tiene sobre la investigación académica y en qué gastan su tiempo y el dinero público nuestras y nuestros investigadores, y dos, el escaso reconocimiento de la investigación en disciplinas del campo de la comunicación, al margen de los clásicos análisis de campañas o marcas; el libro quiere ampliar lo inter y lo transdisciplinar a través de la "movilización del conocimiento", transfiriendo "productos de investigación entre las disciplinas donde estos se generan, hibridando metodologías procedentes del amplio espectro de las ciencias sociales, para facilitar acercamientos que favorezcan su repercusión dentro y fuera del contexto académico". 
Para ello han reunido reflexiones en torno a temáticas como las metodologías visuales y artísticas de investigación en el ámbito comunicativo, el activismo como práctica disruptiva para movilizar el conocimiento, la producción audiovisual y artística desde la escritura, la dirección, la distribución o la edición, y la exploración de las artes performativas en relación con lo digital para componer otras narrativas corporales. Todo eso desde dos corrientes como la artístico-humanista y la científicatecnológica con el fin de plantear los tan necesarios debates interdisciplinares.

El libro está compuesto por una presentación a cargo de la coordinadora del volumen y once capítulos alrededor del arte, lo audiovisual y lo comunicativo con un denominador común, el activismo social, y con una apuesta tan interesante como escasa y arriesgada en la academia española hoy, el compromiso con la transformación social. Nos muestra un panorama de las acciones comunicativas y artísticas desde el activismo social en las universidades españolas, con una muestra representativa que se acerca a una mirada global, si es que esto es posible, sobre las realidades citadas.

El activismo inmerso en el cine y los productos audiovisuales en el artículo de la profesora Mateos (URJC) "el acto fílmico en cuya dinámica puede desplegarse el potencial video activista es un objeto académico no atendido y que sin embargo forma parte de los objetivos que teóricamente rigen el diseño universitario cuando sus bases jurídicas le imponen una misión social"; el cuerpo para habitar los lugares heterotópicos del profesor González Diez (USal) y la profesora Gaona (URJC) "Habitar implica una compleja pluralidad de acciones que van desde los procesos de significación colectivos, la construcción material y simbólica de unos hogares, de unos espacios públicos, la incisión de la memoria colectiva en cada piedra, ángulo y molécula de los espacios, hasta la creación de objetos artísticos en el espacio, o, en definitiva, una estetización del espacio"; la obra artística como método de conocimiento a partir de una obra escénico-musical de la profesora Pérez Custodio (Cons. Sup. Música de Málaga) para "continuar creando más "obras para ser humano" que resulten útiles y generadoras de autoconocimiento"; una reflexión sobre el concepto de patrimonio integral cuestionando "el porqué de la marcada dicotomía entre naturaleza y cultura" para construir un futuro más sostenible de la gestora cultural García Vidal.

Las narrativas transmediales están presentes en tres de los capítulos: en el de los profesores de la Universidad de Granada Alberich, Rosendo y De la Torre que lo presentan como "uno de los territorios discursivos y performativos de mayor vitalidad, presencia y significación contemporánea" para alimentar las acciones de movimientos y organizaciones sociales; en el del profesor Torres, de la Universidad de Málaga, que escribe desde la comunicación transmedial como herramienta para recuperar la memoria histórica a partir del proyecto "La Memoria de los Peces" sobre una de las muchas masacres que asolan Colombia y de cuyo recuerdo la "historia oficial" no reconoce todos los datos por la floja recordación de esos animales acuáticos, y en el que la profesora Martinho y el profesor Alba, también de la UMA, analizan sobre la nueva cultura en red con usuarias y usuarios cuya comunicación les 
hace al mismo tiempo partícipes y generadores de contenidos es lo que a partir de la música como resistencia desde el álbum "Year Zero" del grupo Nine Inch Nails publicado en 2007 con "tres elementos principales: un juego de realidad alternativa (ARG), los contenidos de las canciones (tracks), de su álbum y el contenido generado por el usuario (CGU)".

El caso del artivismo feminista tiene su lugar de la mano del profesor Díaz Morilla (UMA) con el ejemplo de la artista Yolanda Domínguez, cuyo trabajo de performance considera "descontextualizador e irónico" al producir "experiencias que se insertan en la vida diaria con el objeto de despertar la conciencia social y empoderar a las personas a través del arte"; la profesora Navarro, de la Universidad de Valladolid, plantea como punto de partida el valor de la educación como forma de activismo para crear conocimiento, en conjunto entre educadoras y educandas como Montessori y Freire proponían, desde propuestas de interpretación del espacio con el proyecto de investigación artística educomunicativa "Huellas de la ciudad: lecturas del espacio urbano"; las profesoras Castro-Martinez y Pérez Ordóñez (UMA) abordan el arte urbano vecinal como activismo social para recuperar el espacio público en un barrio malagueño promoviendo la sensibilización y participación ciudadana para mejorar la convivencia.

Cierra el libro un artículo de las profesoras Caerols (U. Francisco de Vitoria), Eler y Martins (Universidad Federal de Goiás, Brasil) sobre las propuestas subversivas del lenguaje audiovisual en ese "cruce de caminos entre massmedia, movimientos sociales y la posición que ocupó el videoarte" para hacer artivismo para la transformación social.

La universidad necesita activarse y acercarse a la sociedad en la que se inscribe, y para ello nada mejor que proponer investigaciones que contacten con algunas de las diversas realidades sociales que nos desbordan. Si, además, esas labores hacen que la ciudadanía sepa de ellas y sienta que nuestras académicas e investigadoras tienen los pies en el suelo y sus intereses en temáticas cercanas a la realidad que la afectan, estaremos dando legitimidad a las dos premisas de partida citadas anteriormente.

Las y los académicos necesitan que se sepa de su labor y que no están tan lejos de la sociedad en la que viven. El "artivismo" en la universidad española con proyectos transversales, atravesados por la comunicación, como los que se presentan en este libro, contribuyen a esa cercanía universidad pública-sociedad y a seguir trabajando por la transformación social que afecte alterativamente a las mayorías.

J. Ignacio "Iñaki" Chaves G. Grupo de Investigación Laboratorio de Comunicación y Cultura de la Universidad de Málaga

Almudena Barrientos-Báez Escuela Universitaria de Turismo Iriarte 